\title{
El cambio medioambiental como un asunto de seguridad y sus aportes a la consolidación de la paz territorial
}

Laura Milena Ballén Velásquez

\section{Introducción}

Durante los últimos 40 años el mundo occidental ha experimentado un continuo cuestionamiento a los valores, las instituciones y los proyectos políticos, económicos y culturales que desde el siglo XVIII se convirtieron en el pilar de su desenvolvimiento, ante la identificación por parte de sus propios ciudadanos del incumplimiento de las promesas, bajo las cuales se estructuró el orden social y el surgimiento de efectos negativos no previstos sobre el medio natural y social, que trascendieron a otros contextos socioculturales.

Específicamente, la confianza ciega en el valor de la razón, el avance de la técnica y de la ciencia como liberadoras del ser humano, la búsqueda del progreso mediante la tecnificación y el abandono de las tradiciones y el pensamiento mítico, la visión homogenizadora del mundo y la exaltación del individuo como centro de la vida entraron en crisis a partir de la identificación de los impactos producidos por los proyectos impulsados desde estos supuestos y que fueron el eje de actuación de los Estados liberales modernos.

Situaciones, como abusos de poder, la configuración de un statu quo que anulaba la diferencia y en nombre del progreso ponía en 
marcha acciones contrarias al bienestar y la seguridad de los ciudadanos y de otras poblaciones distantes, junto con la visibilidad cada vez más notoria de los estragos de la industrialización y la urbanización de las sociedades sobre el entorno natural y los paisajes patrimonializados por las sociedades, entre otros aspectos, llevaron al florecimiento de un proceso de organización y movilización social por parte de sectores excluidos, durante finales de los setentas, que fue conocido como la contracultura. Este agrupó a organizaciones feministas, ecologistas, defensores de los derechos raciales y del reconocimiento de la etnicidad, entre otros actores, que planteaban la necesidad de reestructurar los cimientos de la sociedad, superar la individualización y el etnocentrismo, fortalecer la democracia radical y repensar la relación con el entorno natural.

En este marco de reflexión, que se prolongó hasta entrado el siglo XXI, se plantearon distintos debates con respecto a la relación hombre-naturaleza-cultura, el reconocimiento de la diferencia, la vulnerabilidad del ser humano ante las instituciones sociales y los fenómenos naturales, los fundamentos y los límites de la acción estatal, la concreción de los derechos sociales, la noción misma de desarrollo como progreso fundamentado en el impulso de las fuerzas productivas para estimular el crecimiento económico y las relaciones entre Estados para la gestión de problemáticas comunes; introduciéndose en cada uno de ellos la preocupación por la seguridad humana.

Precisamente, con la visibilidad adquirida por las situaciones de degradación ambiental, los temores derivados de los accidentes nucleares registrados en los años setenta y ochenta, así como la incorporación en la agenda internacional de la necesidad de combatir la pobreza mundial, el problema de la seguridad transitó de una visión clásica enfocada al mantenimiento del orden social y la integridad territorial (seguridad nacional) a la inclusión del interés por el bienestar y la ampliación de las capacidades humanas y por la garantía de las condiciones materiales y ambientales que permitan satisfacer dichos aspectos.

De esta manera se produjo, en el contexto definido por Beck (1989) como modernidad reflexiva, una mayor preocupación por el riesgo y la vulnerabilidad derivada del desarrollo de las fuerzas productivas que detonó el acercamiento entre las agendas de la seguridad y el 
medio ambiente, conformándose, a su vez, una nueva agenda, la de la seguridad medioambiental, cuya estructuración no ha estado ajena a controversias y se ha dado de manera incremental, de acuerdo con el modo como se han construido socialmente las visiones sobre el cambio medioambiental y sus afectaciones para la vida humana.

En consecuencia, el presente capítulo tiene como propósito esbozar algunas reflexiones sobre las distintas maneras como se han articulado hasta el momento los problemas de la seguridad y la gestión del medio ambiente, así como las implicaciones derivadas de la forma como se ha producido este acercamiento en la definición y el tratamiento de los desafíos que aquejan a las sociedades contemporáneas, donde el cambio climático se erigió como la principal amenaza para la humanidad, en detrimento de otras situaciones igualmente relevantes.

Se pretende argumentar que la percepción y la conceptualización del cambio medioambiental como un asunto de seguridad es un constructo social derivado de la lucha política entre distintos actores por mantener o promover un orden social particular cercano a sus intereses, que se ha alimentado de la circulación y la confluencia de distintas matrices discursivas sobre la relación hombre, naturaleza y cultura y el papel de la ciencia y de las instituciones sociales para generar y mantener acuerdos sociales sobre la administración y la gestión de los elementos que brinda la naturaleza.

A través del tiempo se ha transitado del predominó inicial de una visión catastrofista de los impactos derivados de la acción humana sobre el medio ambiente, que acentuaba el riesgo de la desaparición de la propia especie y demandaba una transformación radical del orden social, hacia una representación moderada, inspirada en los presupuestos de la modernización ecológica, confiada en el progreso de la ciencia y los ajustes tecnológicos como mecanismos para atender y frenar las amenazas derivadas de las trasformaciones medioambientales.

En este tránsito se ha dado una escisión en cómo se abordan las distintas dimensiones que abarca el cambio medioambiental como asunto de seguridad, privilegiándose la caracterización de la dimensión climática como la mayor amenaza para la humanidad, lo cual ha implicado perder la mirada de conjunto y la subordinación a este fenómeno de otras temáticas igualmente relevantes que deben ser tratadas 
con la misma prioridad y de manera articulada, tales como las políticas de población y de apropiación, manejo y distribución de los servicios ecosistémicos como bienes públicos, y la soberanía alimentaria entre otros aspectos.

La base del problema del cambio medioambiental como un asunto de seguridad y su tratamiento radican en la movilización del temor como fundamento para promover la cohesión social y detonar una acción orientada a contrarrestar las situaciones y los procesos que pueden desestabilizar y recomponer el orden social existente, estructurado a partir de una distribución excluyente de los satisfactores de las necesidades humanas y de una relación asimétrica con la naturaleza.

Sin embargo, en la propia securitización del medio ambiente pueden encontrarse soportes tanto para redefinir los fundamentos de las relaciones entre el hombre, la naturaleza y las diferentes comunidades humanas, desde perspectivas centradas en la equidad y el reconocimiento de la complejidad; como para generar capacidades basadas en parámetros alternativos que permitan construir ágilmente acuerdos políticos incluyentes y socialmente vinculantes orientados al manejo y la protección de los ecosistemas y sus componentes en pro del bienestar humano y de los demás seres vivos.

Estos parámetros son el reconocimiento de la interrelacionalidad de las distintas dimensiones y escalas territoriales en las que se desenvuelve la vida social, la diversidad de interacciones entre la naturaleza y la cultura, así como el carácter protagónico que revisten los territorios como actantes para sentar las bases de una convivencia armónica, eje que debe estructurar el gobierno de las sociedades. Lo anterior supone trascender la consideración de los territorios como simples contenedores de elementos naturales, actores y procesos, e identificarlos como organismos vivos, que soportan la concreción de la paz, entendida como un estado de concordia entre diversas perspectivas, las cuales, pese a su diversidad, comparten un sentido socialmente construido del bien común como elemento unificador.

Para sustentar los elementos señalados anteriormente, este documento se estructura en cuatro partes. En la primera se plantean algunos elementos teóricos sobre la construcción social de los problemas públicos y sobre cómo la trayectoria a partir de la cual la seguridad y 
el medio ambiente han sido definidos como tal. En un segundo momento se analiza la manera como hasta el momento se han construido sociopolíticamente las manifestaciones del cambio medioambiental como un problema para los Estados y el orden internacional y las agendas dominantes al respecto y su vínculo con las agendas de la seguridad. En este sentido se abordan problemáticas como el cambio climático, la producción, la administración y la gestión de las fuentes de energía, así como la gestión conjunta de bioregiones que atraviesan varios estados o que resultan fundamentales para la humanidad en su conjunto y su visibilización como asuntos de seguridad.

Posteriormente, en el tercer apartado se discuten las posibilidades que ofrece el tratamiento del cambio medioambiental como un asunto de seguridad para estructurar un marco de relaciones que garantice el desarrollo territorial y la paz, tomando como referente el caso colombiano. Finalmente, se plantean algunas conclusiones.

\section{La construcción sociopolítica de la seguridad y de las dinámicas ambientales como problemas públicos}

Desde tiempos ancestrales, la preocupación por la preservación de la vida, el control de los factores del medio externo que pueden alterar la sensación de bienestar y la búsqueda de la protección antecarencias y peligros externos han sido el motor del devenir de la humanidad y el fundamento para el establecimiento de la vida en comunidad, la definición de roles diferenciados y la instauración de instituciones encargadas del manejo de dichos aspectos.

Precisamente, la observación del medio natural y la identificación de la periodicidad de sus ciclos y de las afectaciones que suponían para el ser humano llevaron a la invención de herramientas para gestionar dichos aspectos que detonaron un salto evolutivo, como fueron el desarrollo de la agricultura y la consecuente configuración de los primeros asentamientos humanos, ámbitos desde donde surgieron las primeras instituciones sociales para regular las interacciones, los conflictos y las tensiones propias de la convivencia. 
De este modo, las primeras formas de organización social se estructuraron a partir de la unidad entre el hombre, la naturaleza y la cultura, es decir, desde cosmovisiones particulares sustentadas en la interacción con el entorno, que condujeron a la demarcación de las primeras formas de territorialidad, entendida esta última no solo como la demarcación de un dominio geográfico, sino también como la delimitación de un adentro y de un afuera, de "nosotros" y un "ellos", que refuerza la unidad.

En este marco se definieron las primeras nociones de raza en torno a las cuales se establecieron distintas formas de dominación social, así como proyectos orientadores que implicaban la ocupación y la conquista de otros territorios, como también la apropiación de sus recursos. Así surgieron las primeras estratificaciones internas, la caracterización a otros pueblos como barbaros y el desarrollo de proyectos expansionistas hacia otros territorios, todo lo cual significó el desarrollo de tecnologías para la guerra, tales como la estrategia o el arte de conducir las tropas a la victoria, y la configuración mediante el sometimiento y los dispositivos de control de las grandes civilizaciones el mundo antiguo, algunas de las cuales cimentaron el desarrollo posterior del mundo occidental.

Desde entonces, se configuró en occidente una visión de la seguridad centrada en la dimensión militar y en el control del uso de la fuerza, como fundamento del ejercicio del poder, que se fortaleció en el proceso histórico de configuración del Estado absolutista y su tránsito hacia el modelo del Estado nación moderno. Como lo plantea Michel Foucault en Defender la sociedad (1977), la historia del Estado es la historia de la configuración de un saber político, (las tecnologías de segurida), orientado a la regulación de la población a partir de distintos mecanismos que ejercen control sobre la vida misma.

Como lo muestra Foucault (1978) en su estudio sobre el nacimiento de la gubernamentalidad, desde los primeros siglos de la era cristiana se estructuró en Europa una forma de racionalidad del poder fundamentada en el control sobre la vida de las personas, cuyos objetivos y acentos transitaron del biopoder a la preocupación por el establecimiento del gobierno y su reforzamiento. En dicho desplazamiento, ocurrido en el tránsito del Estado territorial del siglo XVIII al Estado 
de población en el siglo XIX, se introdujeron nuevos problemas, técnicas y dispositivos de poder orientados a lograr un equilibrio global, es decir, la seguridad del conjunto respecto de sus peligros internos.

Con ello se dio un cambio en la racionalidad, marcado por el paso de la preocupación por la soberanía del territorio al problema de la regulación de las poblaciones, lo que significó la innovación de las prácticas gubernamentales y con ello la instauración de una sociedad de seguridad, en la cual el Gobierno, más que una autoridad pública, constituye una técnica específica para manejo de las propias poblaciones desde una racionalidad económica que equipara la sobrevivencia de la población con la subsistencia del Estado. De este modo el problema de la seguridad se configura como un problema de administración de la vida.

Las tecnologías del poder desarrolladas en Europa, mediante las cuales se pretendía defender la sociedad de los peligros originados en el propio cuerpo social, orientaron la acción del Estado al ejercicio del biopoder: el control preventivo de los procesos propios de la vida, tales como el nacimiento, la muerte, la reproducción, la enfermedad, entre otros (Foucault, 2001, p. 220).

Así el propio Estado, como tecnología del poder, ha tenido como uno de sus fundamentos el problema mismo de la seguridad asociado al tema del control de la vida. Este incorporó progresivamente varios saberes como la estadística, la demografía, la higiene pública, entre otros, los cuales han estado encaminados a garantizar la atención de los factores globales generadores de las problemáticas de sus asociados, como un mecanismo para garantizar su reproducción, a los cuales se han añadido con el tiempo otras temáticas que responden a ese mismo principio básico.

Uno de los últimos ámbitos involucrados en el ejercicio del biopoder, que no es ajeno al tema de la natalidad y la morbilidad, es como lo señala Foucault el de:

[...] las relaciones entre la especie humana, los seres humanos como especie, como seres vivientes y su medio, su medio de existencia, ya se trate de los efectos en bruto del medio geográfico, climático e hidrográfico; los problemas, por ejemplo, de los pantanos, las 
epidemias ligadas a la presencia de terrenos pantanosos durante la primera mitad del S XIX, también el problema de un medio que no es natural y tiene efectos de contragolpe sobre la población; un medio que ha sido creado por ella. Ese será esencialmente el problema de la ciudad. (Foucault, 2001, p. 222)

Por lo tanto, desde la consolidación del Estado moderno, como forma institucional, en la que toma concreción el proyecto político, económico y cultural de la modernidad y que fundamentó el desarrollo del capitalismo, ha existido una asociación entre los problemas de la seguridad y el medio ambiente, que se vuelve invisible en las propuestas contractualistas que pretendieron situar los orígenes y los fundamentos que dieron lugar a esta estructura de organización y dominación de la sociedad.

En los marcos liberales clásicos, como los propuestos por Hobbes y Locke, la conformación del Estado se explica y se legitima por la necesidad de superar el estado de naturaleza o anarquía total, que impedía el disfrute de las libertades individuales y el ejercicio de la propiedad. Desde estas visiones el Estado surge como el gran Leviatán encargado de proteger y garantizar la seguridad de sus asociados y la paz necesaria para el desarrollo de la libre iniciativa privada, a partir de una sesión de soberanía por parte de estos, relacionada con el ejercicio de la violencia.

De este modo, al justificar el monopolio de la violencia física legítima y el control de un territorio como atribuciones propias del Estado y reguladas mediante un contrato social establecido entre este y los ciudadanos, y en las relaciones entre Estados una visión de la seguridad, entendida como seguridad nacional, en la cual las preocupaciones se orientaban a mantener el control territorial, identificar las amenazas externas e internas, y prevenir riesgos que pudiesen afectar la estabilidad del orden social existente.

Dicha visión predominó desde finales del siglo XVIII hasta mediados del siglo XX, exportándose de Europa a otros contextos socioculturales donde se impuso la figura del Estado nación sobre las antiguas estructuras coloniales y los reductos de instituciones sociales previas a la conquista y que no desaparecieron del todo durante el periodo 
colonizador. No obstante, por efecto de la propia evolución de las sociedades occidentales y de las dinámicas de carácter económico, político y cultural que se registraron a su interior, empezaron a cuestionarse los derroteros y los cimientos de la propia sociedad y con ello se dio tránsito a un replanteamiento posterior de la noción de seguridad.

Identificar los desequilibrios derivados de la intervención débil del Estado en la economía bajo el predominio de las teorías económicas liberales clásicas, junto con las condiciones precarias de vida de los sectores trabajadores industriales y el incumplimiento de las promesas de redistribución por goteo de los beneficios derivados del crecimiento económico, supusieron precisamente un replanteamiento de la relación Estado-sociedad con implicaciones posteriores a la hora de comprender la seguridad y las agendas públicas dentro de los Estados nación.

De este modo, la intensión de mantener la estabilidad del orden social existente significó la consolidación de la biopolítica como fundamento del ejercicio del Gobierno y con ello la ampliación de los campos de intervención del Estado hacia diversas esferas de vida social y económica; al punto de generarse un control centralizado y burocratizado de las poblaciones, basado en la promesa de la redistribución y la satisfacción de ciertas garantías materiales (derechos económicos, sociales y culturales). Con lo anterior, la seguridad en el plano interno se estructuró a partir de la confianza en las instituciones de proveer el bienestar de las poblaciones.

Simultáneo a lo anterior, en lo que se refiere a las relaciones entre Estados se mantuvo una visión de la seguridad fundamentada en el realismo político, a partir del quiebre del idealismo planteado a comienzos de siglo y que orientó la conformación de la Sociedad de las Naciones. En este plano de la realidad, el problema de la seguridad se continuó planteando en términos del mantenimiento de la integralidad del control territorial y la defensa ante amenazas externas.

Posteriormente, en la década de los setentas se produjo internamente un quiebre en la confianza en el Estado y en las instituciones sociales tradicionales, como consecuencia del excesivo intervencionismo en distintas esferas de la vida social, lo que trajo nuevamente al centro del debate al individuo y a la dimensión humana. 
En este contexto, que corresponde a la década de los setentas del siglo XX, se abogó por una nueva visión de desarrollo, centrada en el ser humano, específicamente en la generación de condiciones que permitiesen la satisfacción de las necesidades materiales e inmateriales de los individuos, el acceso a las instancias y los procesos de toma de decisión referentes a los asuntos que los aquejan y la protección contra las amenazas derivadas de las privaciones que suponen los conflictos violentos, la pobreza y el deterioro del medio ambiente.

Las nuevas visiones del desarrollo constituidas en torno a las propuestas de autores como Manfred MaxNeef y Amartya Sen, quienes articularon a esta noción las preocupaciones por la democracia y la ampliación de las libertades de decisión y actuación respectivamente, detonaron una nueva comprensión de la seguridad centrada en el ser humano. Lo anterior permeó no solo las agendas internas de los estados, sino que además fue acogida por organismos internacionales para orientar su accionar y los compromisos suscritos entre estos y los propios estados.

Lo anterior se ve reflejado en el Informe sobre el Desarrollo Humano publicado en 1994 por la ONU, el cual asumió una nueva conceptualización de la seguridad humana y la asimiló con la protección contra las amenazas generadas por la enfermedad, el hambre, el desempleo, el delito, el tráfico de estupefacientes, la represión de las poblaciones, la violación de los derechos humanos y las condiciones del medio ambiente, entre otros elementos. Esta perspectiva partió de catalogar como estrecho el carácter atribuido al concepto de seguridad en el marco de la Guerra Fría, en el cual esta era vista simultáneamente como el control de las agresiones externas que puedan afectar al territorio de una nación, la protección de los intereses nacionales en la política exterior y como seguridad mundial ante la amenaza de un holocausto nuclear (PNUD, 1994).

Así, para la ONU se ampliaron los contenidos y los campos de acción en materia de seguridad centrándolos en los intereses cotidianos de la ciudadanía, desde una perspectiva que integra las dinámicas de orden interno con el contexto externo, pues según este organismo: 
Cuando la seguridad de las personas es atacada en cualquier parte del mundo, es probable que todos los países resulten involucrados. El hambre generalizada, los conflictos étnicos, la desintegración social, el terrorismo, la contaminación y el tráfico de estupefacientes ya no son acontecimientos aislados y confinados dentro de las fronteras nacionales. Sus consecuencias repercuten en todo el mundo, e incluso cuando no lo hacen, las comunicaciones mundiales las imponen a nuestra conciencia. (PNUD, 1994, p. 22)

Consecuente con lo anterior, la propuesta de la ONU implicó un nuevo marco de trabajo conjunto y de colaboración entre los Estados, fundamentado, en los siguientes supuestos: 1) es más eficiente la prevención en las bases donde pueden gestarse los fenómenos que la atención humanitaria luego de que han aparecido los problemas; 2) el carácter universal de la preocupación por la seguridad humana, lo cual implica reconocer que existen muchas amenazas que son comunes a toda la población independientemente de si vive o no en países ricos y pobres; 3) la interdependencia de los componentes de la seguridad humana; 4) la comprensión del ser humano como centro de la seguridad, elemento que supone dar prioridad a la atención de los asuntos de su vida cotidiana.

Basándose en los supuestos señalados, el PNUD definió la seguridad humana de acuerdo con dos dimensiones, articuladas a la definición de desarrollo humano, siendo estas:

En primer lugar, significa seguridad contra amenazas crónicas como el hambre, la enfermedad y la represión. Y, en segundo lugar, significa protección contra alteraciones súbitas y dolorosas de la vida cotidiana, ya sea en el hogar, en el empleo o en la comunidad. Dichas amenazas pueden existir en todos los niveles de ingreso y desarrollo de un país. La pérdida de la seguridad humana puede ser un proceso lento y silencioso o una emergencia abrupta y estridente. Puede ser obra humana, como resultado de opciones erradas de política. Puede ser consecuencia de las fuerzas de la naturaleza. O puede ser una combinación de ambos casos, como ocurre con frecuencia cuando el deterioro del medio 
ambiente desemboca en un desastre natural, seguido de la tragedia humana. (PNUD, 1994, p. 26)

Junto con estos elementos, la propuesta sobre la seguridad humana integra dos componentes, la libertad respecto del miedo y de la necesidad, centrándose en el segundo e incorporando la preocupación por la seguridad alimentaria, la seguridad económica, la seguridad en materia de salud, la seguridad ambiental, la seguridad personal, la seguridad de la comunidad y la seguridad política.

La introducción de los distintos componentes señalados como asuntos de seguridad al finalizar el siglo XX, en particular los relacionados con el medio ambiente, es así mismo el producto de una trayectoria que inició a finales del siglo XIX y que solo logró concretarse por la presión de los acontecimientos y la movilización del movimiento ecologista. Lo anterior corresponde a la visibilización del cambio medioambiental como un asunto relevante para la humanidad.

Si bien como producto del avance de la industrialización, ya durante el siglo XIX eran perceptibles algunas alternaciones al medio natural y las situaciones de degradación ambiental que dieron origen a los primeros planteamientos del pensamiento ecologista. El interés por el medio ambiente no trascendió de una preocupación paisajista, siendo un tema secundario que no permeó las agendas públicas estatales e internacionales, ni de las ciencias sociales.

Como lo señala Lezama (2004), la construcción y la definición social de los problemas ambientales fue un asunto descuidado por las ciencias sociales, en particular, por los autores, clave en su nacimiento y consolidación como disciplinas en el siglo XIX y que más tarde serían considerados como padres fundadores del pensamiento social. Específicamente, como lo sugiere Eder (1996, citado en Lezama, 2004), en las propuestas de Marx y de Durkheim se asume una visión naturalista de la sociedad, en la medida en que juzgan su desenvolvimiento de acuerdo con los estándares de reproducción y evolución de la propia naturaleza, particularmente mediante procesos como la adaptabilidad y el control de los recursos que permiten la sobrevivencia (Eder, 1996, citado en Lezama, 2004, p. 27). Con ello, estos autores como el conjunto del pensamiento social clásico caen en un reduccionismo 
que termina por asimilar la construcción social de la naturaleza a una apropiación social de esta, consistente en su sometimiento, desde una relación de exterioridad y dominio.

Por el contrario, para Eder la construcción social de la naturaleza se desenvuelve en una interacción cognitiva, moral y estética entre la sociedad y su entorno natural. La apropiación de la naturaleza no es solo un proceso de adaptación del ser humano a esta, sino que, contrariamente a lo que plantea la postura naturalista de la relación naturaleza-sociedad, la propia naturaleza es considerada como un producto simbólicamente construido y no algo objetivamente dado.

La comprensión de la naturaleza, como un producto social, propuesta por el constructivismo se constituye en uno de los marcos analíticos a partir de los cuales se ha podido establecer la emergencia de los problemas ambientales como asuntos socialmente relevantes y la forma como estos han sido delimitados como tal. Esencialmente, esta perspectiva ha permitido visibilizar cómo la identificación del cambio medioambiental es el resultado de la interacción entre diversas matrices discursivas, cuyo encuentro ha permitido la estructuración de una forma particular de entender las situaciones del deterioro medioambiental.

Uno de los principales aportes de la perspectiva constructivista en la interpretación de los problemas ambientales es la identificación de cómo la relevancia o la irrelevancia de los problemas ambientales no depende en sí misma de la magnitud del daño que provocan, sino de la manera como son internalizados por la sociedad en los ámbitos normativos, cognoscitivos y simbólicos. Planteado de esta manera, los problemas medioambientales no existen en sí mismos, sino que se configuran como tal a partir de la valoración social, ya que son las normas sociales las que posibilitan que una situación adquiera el estatus de objeto de preocupación (Lezama, 2004, pp.13-14).

Sin embargo, la estimación social no es único factor conducente a la incorporación del daño ambiental empíricamente demostrable como amenaza y como asunto que demanda la gestión estatal. Además de las normas sociales, los productos del conocimiento y del mundo simbólico contribuyen a que lo ambiental sea considerado como una amenaza para la vida colectiva o una fuente de daño, científicamente demostrable que demanda intervención, tal como quedó demostrado 
en la década de los setentas. Allí, la combinación de cambios en las normas sociales, los avances científico-tecnológicos y la movilización de emblemas en los que planteaba el peligro de extinción de la tierra y a la vida misma, determinó la inclusión de las manifestaciones del cambio medioambiental en la agenda pública (Lezama, 2004, p. 14).

Efectivamente, la movilización de símbolos y emblemas mediante los cuales se caracterizó a la tierra como hogar en peligro, en particular, la difusión de la primera imagen satelital de la tierra, y la presión de las organizaciones verdes durante la década de los sesenta fueron factores determinantes para que el llamado a la acción frene el cambio medioambiental y se incorporase en las agendas de los diferentes actores públicos y privados, tanto en las escalas nacional e internacional, y se planteasen las primeras medidas para atender el fenómeno (Hajer, 1995).

Los procesos de confluencia entre emblemas, actores y soportes tecnológicos, como el experimentado a finales de los sesenta, reafirman como una situación social, pese a tener una manifestación física concreta, puede no ser percibida y tratada como un problema público, si no es construida como tal para una sociedad; razón por la cual los empresarios político y los recursos simbólicos y de información que despliegan es vital para comprender de una situación como problema público.

Desde el campo del análisis de las políticas públicas, la perspectiva de la construcción de las situaciones sociales como problemas socialmente relevantes, objeto de la acción pública, ha sido reconocida por diversos autores y enfoques que van desde el policy cicle (Jones, 1970), que distingue entre la construcción de problemas sociales como problemas que demandan una intervención pública y el proceso de inclusión en la agenda política (agenda setting); hasta las propuestas de Lenoir (1989, citado en Roth, 2002), Cobb y Elder (1972), Meny y Thoening (1992) y Garroud (1990), quienes caracterizan aspectos como las fases de construcción de los problemas, los modos y los modelos ${ }^{1}$ de inscripción en la agenda política respectivamente.

1 Dentro de los modelos propuestos por Garraud (1990) se identifican cinco tipos de movilización, a partir de la combinación de actores y 
En general, los marcos teóricos sobre la construcción de las situaciones sociales como problemas públicos y su incorporación en la agenda gubernamental señalan que en dichos procesos resulta fundamental la manera como los actores afectados logran traducir sus demandas en los términos predelimitados por el sistema político, siendo precisamente el modo como se delimitan los problemas el centro de la disputa entre los actores. Más que la selección de los problemas por incorporar en la agenda, lo que importa es el contenido que se les atribuye, ya que en torno a estos existen varias concepciones e intereses.

Por lo tanto, en la transformación del cambio medioambiental y de la seguridad, como problemas públicos, y en su inclusión dentro de las agendas gubernamentales nacionales y supranacionales el centro de las controversias y las tensiones ha estado en la forma como se delimitan y se definen dichos asuntos como problemas públicos, dados los temores de los actores en relación con las repercusiones que esto pudiese tener sobre sus intereses y sobre la estructura misma de la sociedad. Los debates no se plantean solo porque existan diferentes visiones ante los problemas, sino porque la delimitación puede desbalancear las complejas relaciones de poder existentes y suponer algunas medidas que imponen restricciones u obligaciones adicionales con costos para los actores en términos económicos y políticos.

Las tensiones en torno a la definición y la delimitación de estos asuntos se complejizaron aún más cuando se planteó la existencia de una interconexión entre ellos mismos, a partir de la mediación ejercida por los científicos, los propios gobiernos, la academia y los miembros de los movimientos ambientalistas, quienes para dar mayor trascendencia y visibilidad a las repercusiones del daño medioambiental y, por lo tanto, forzar la acción de los gobiernos y del sistema internacional, empezaron a cuestionar como sus efectos podrían significar una explosión de conflictos bélicos entre Estados o presionar y profundizar los choques hasta entonces existentes.

recursos, siendo estos los de la oferta política, de la mediatización, la anticipación y la acción corporativa silenciosa. 
Fue precisamente a partir del discurso del desarrollo sustentable y de las diversas conceptualizaciones, las imágenes, las representaciones y las narrativas que se establecieron que se logró la articulación entre las visiones del cambio medioambiental, como un asunto que compete a toda la humanidad y los problemas de seguridad, predominando una imagen catastrófica como factor movilizador de la acción.

La circulación de una imagen negativa de las consecuencias del cambio medioambiental sobre la vida en la tierra que predomina hasta nuestros días, a partir del intercambio entre científicos, movimientos sociales y decisores públicos, sentó las bases para la estructuración de un régimen internacional para el tratamiento del medio ambiente y los efectos de la presión antropogénica sobre este, el cual no ha estado exento de contradicciones. Por el contrario, este régimen ha asumido de forma tenue la caracterización del deterioro ambiental como un problema de seguridad al centrar su preocupación en los problemas del clima, derivados de la emisión de gases, que primero fueron delimitados como el efecto invernadero y posteriormente como cambio climático.

En la estructuración incremental de la agenda de la seguridad medioambiental, como asunto de interés público en el plano internacional, fue la conferencia de Estocolmo (Suecia), celebrada en 1972, el hito fundacional en la medida en que, si bien no traza la caracterización del fenómeno como un asunto netamente de seguridad, reconoce sus implicaciones para la estabilidad del orden social y la paz en el ámbito internacional.

La conferencia de Estocolmo definió veintiséis principios orientadores comunes para conducir la preservación y la mejora del medio ambiente humano en los que se asumen como directrices las siguientes orientaciones:

- La necesidad de promover el desarrollo como vía para superar la degradación ambiental;

- La planificación racional para superar los conflictos entre las necesidades de protección al medio ambiente y de desarrollo (principios 13 y 14) y administrar o controlar los recursos naturales;

- La aplicación de la ciencia y la tecnología para identificar, prevenir y controlar los riesgos y los problemas ambientales (principio 18); 
- La promoción de la educación ambiental (principio 19) y de la investigación científica, así como la difusión de sus avances hacia los países en desarrollo (principio 20);

- El reconocimiento de los principios del derecho internacional y del derecho soberano de los pueblos de explotar sus recursos según sus propias políticas ambientales con la responsabilidad de no causar daños en el medio ambiente de otros Estados (principio 21);

- La cooperación de los países en condición de igualdad, mediante instrumentos multilaterales o bilaterales para controlar, prevenir y reducir los efectos ambientales de las actividades humanas, respetando la soberanía de los Estados.

De esta manera, los principios adoptados por los Estados participantes en la conferencia de 1972 y en los acuerdos posteriores que se sucedieron en las tres décadas siguientes, significaron la concreción y el cierre discursivo de los asuntos ambientales como aspectos trascendentales para la concreción de las aspiraciones de seguridad humana y de desarrollo, al punto tal que en la definición de los Objetivos de Desarrollo Sostenible, realizada en 2016 se adoptó una conceptualización que articula la paz, la prosperidad y la protección al planeta.

La agenda Objetivos de Desarrollo Sostenible se define a sí misma como los objetivos mundiales, es decir, como un llamado a la acción conjunta por parte de los distintos Estados, independientemente de su condición de renta, para erradicar la pobreza, mejorar las condiciones del planeta y con ello la vida de las personas del presente y de las generaciones futuras, garantizando el disfrute de la paz y de la seguridad. Como tal, la agenda esboza diecisiete objetivos y un conjunto de metas específicas por alcanzar antes de 2030, con la concurrencia de los gobiernos, el sector privado, la sociedad civil y la ciudadanía.

De los diecisiete objetivos trazados, diez hacen referencia a asuntos relacionados con el medio ambiente y la seguridad, siendo estos: 6. Agua limpia y saneamiento, 7. Energía asequible y no contaminante, 9. Industria, innovación e infraestructura, 11. Ciudades y comunidades sostenibles, 12. Producción y consumo responsables, 13. Acción 
por el clima, 14. Vida submarina, 15. Vida de ecosistemas terrestres y 16. Paz, justicia e instituciones sólidas.

La definición de los objetivos mencionados se fundamenta en la matriz discursiva del desarrollo sostenible, emblema unificador, producto de la movilización de varios actores y perspectivas, en torno al cual subyacen diversas interpretaciones, que en últimas explican la no concreción de la apuesta por alcanzar una contención del deterioro medioambiental. Esta matriz se remonta a las conceptualizaciones sobre el ecodesarrollo, formuladas en los setenta, en un marco de interpretación del fenómeno que suponía la necesidad de reestructurar el sentido y el alcance del desarrollo; estas conceptualizaciones fueron remplazadas por visiones moderadas, escépticas de la necesidad de un revolcón de la sociedad y a favor de conceder mayor protagonismo a la ciencia y la tecnología como portadoras del saber necesario para redireccionar los procesos y compatibilizar la protección ambiental con las apuestas de desarrollo y crecimiento económico.

Con el predominio del discurso del desarrollo sostenible se consolidó no solo la mirada del cambio medioambiental como un problema derivado de desajustes técnicos, generador de varios riesgos para la humanidad, que pueden ser gestionados y controlados mediante la innovación tecnológica y la cooperación entre distintos actores. Además de ello, se estructuró un marco de referencia sobre los problemas ambientales que supeditó las distintas dinámicas de degradación y deterioro al fenómeno del cambio climático, siendo este la gran amenaza a la seguridad humana y a la estabilidad del orden internacional.

La identificación del cambio climático, como la principal problemática de nuestra, era significó, por un lado, un nuevo marco de relación y articulación entre lo público y lo privado y entre los mismos estados, fundamentado en el establecimiento de responsabilidades comunes, pero diferenciadas para la gestión del problema; y por otra, una ventana de oportunidad para el retorno del Estado, luego de una década en la que se propugnó su retraimiento y la asignación al mercado de la responsabilidad de regular la distribución de bienes y satisfactores de las necesidades de las colectividades.

Las acciones sugeridas para hacer frente al cambio climático se han planteado a partir de la necesidad de que los distintos agentes 
sociales asuman un compromiso con el tema, reorientando sus conductas y asumiendo la financiación de las intervenciones requeridas, en particular, la industria y el sector privado en general, con lo cual se adoptan implícitamente las visiones sobre la gobernanza que la asimilan como un marco de articulación para el planteamiento de acuerdos colectivos y su concreción en acciones específicas.

Además de lo anterior, con este fenómeno irrumpieron cuestionamientos sobre cuál debe ser el rol del Estado y de la sociedad misma en la gestión de los resultados, si debe retornarse o no a la planificación. Tal como lo sugiere Giddens (2010), la expansión del poder humano ha generado un camino sin retorno en el que se han liberado distintas fuerzas que ahora están fuera de su control, pero que inevitablemente demandan el planteamiento de cursos de acción para detenerlos. Una de estas posibilidades puede encontrarse en el Estado como institución y en los Estados con mayores capacidades políticas, ya que atender las problemáticas requiere disponer de herramientas para el control, el seguimiento y vigilancia de los acuerdos suscritos entre los distintos actores, aspectos que estas organizaciones pueden abordar con mayor facilidad.

Alrededor del cuestionamiento sobre el papel que desempeña el Estado y el retorno de la planificación subyacen una cercanía con las propuestas de la modernización ecológica, una apuesta teórica y política que concibe la capacidad del ser humano para redireccionar los procesos de deterioro ambiental, y que minimiza el carácter catastrófico dado a los problemas ambientales de nuestra era. El ser humano confía en la ciencia y en el desarrollo dispositivos tecnológicos, dentro de los que cabrían las tecnologías del poder, como herramientas para gestionar las externalidades negativas resultantes de los procesos productivos y de la acción humana, en general, y para garantizar el bienestar y la continuidad de la especie.

Con base en las reflexiones de la modernización ecológica, en las que puede enmarcarse el trabajo de A. Giddens, la mejor forma para hacer frente a las dinámicas del cambio medioambiental es la cooperación. En especial, se asume que la transferencia de información, conocimientos y tecnología, así como la ayuda directa entre organizaciones y Estados puede ser el camino para contrarrestar las amenazas, junto 
con la capacidad política para movilizar a los ciudadanos en el plano interno y comprometer a los Estados en el plano externo.

La postura optimista de la modernización ecológica contrasta con la visión de Ulrich Beck sobre el carácter de la sociedad contemporánea y sus posibilidades de enfrentar el cambio medioambiental. Beck (2006) advierte la extrema individualización que marca nuestras sociedades, la pérdida de convocatoria de las formas de organización y de acción colectiva, así como la interiorización y la socialización de los riesgos como aspectos propios de la fase actual de la modernidad (modernidad reflexiva) que limitan la capacidad de enfrentar los desafíos civilizatorios.

El rasgo central de la modernización reflexiva es la continua producción y la individualización de los riesgos como procesos sociales predominantes, en los cuales se ponen en entre dicho las instituciones sociales propias del proyecto de la modernidad. En especial, la lógica del reparto de la riqueza es sustituida por el reparto de los riesgos generados por el desarrollo económico y técnico-científico propio de la modernización; siendo estos daños irreversibles, producidos socialmente, que tienen la capacidad de destruir la vida sobre la tierra.

Los peligros que suponen los riesgos para la civilización moderna se caracterizan, según Beck (2006), por su carácter global (supranacional) y por la capacidad que tienen de afectar por igual a los distintos actores sociales independientemente de su condición de clase social. No obstante, el mismo autor advierte las condiciones asimétricas en las que se encuentran las clases sociales para responder a los desafíos que les imponen los riesgos —estando en mayor posibilidad de enfrentarlos las clases con mayores recursos- y cómo estos al final de cuentas terminan por devolverse a quienes los producen.

Para Beck, la sociedad moderna es una sociedad catastrófica que guarda el germen de su propia destrucción, pues los riesgos son generados por el mismo hombre y las instituciones que creó, en especial, la ciencia. Para el autor, esta última es la responsable de los riesgos y paradójicamente se convirtió simultáneamente en causa, instrumento de definición y fuente de solución de los mismos riesgos (Beck, 1998, p. 203, citado en Oltra,2005). Por lo tanto, en este marco interpretativo, la ciencia es la generadora de los desastres ecológicos y de los 
peligros nucleares, así como de la contaminación y demás fenómenos que afectan la vida humana.

Para la perspectiva de la sociedad del riesgo, los peligros ecológicos no existen en sí mismos, sino que "se definen, ocultan o dramatizan estratégicamente en la esfera pública con la ayuda de material científico suministrado a tal efecto" (Beck, 2006, p. 34), por lo tanto, es un constructo social en el que intervienen distintos actores y resultan determinantes los conocimientos que estos poseen y perciben sobre los peligros que los rodean.

Con lo anterior, Beck puso de manifiesto varios aspectos que rescata Oltra (2005): la desmitificación de la ciencia en sus ámbitos interno y externo, es decir, el cuestionamiento a su comprensión como ámbito neutral y fuente de progreso (Oltra, 2005, p. 140), lo cual es un reconocimiento del carácter politizado de la ciencia y su utilización como instrumento para delimitar de forma particular lo que se define como riesgo, siendo este último socialmente construido.

Pese a estos cuestionamientos, la ciencia al ser fuente generadora de riesgos es catalogada, de acuerdo con la conceptualización de Beck (2006) como la solución a los problemas que ella misma genera y como eje central para su propia reflexividad. Sin embargo, esta capacidad se ve limitada por la imposibilidad del conocimiento científico de evaluar las soluciones culturalmente aceptables.

Coincidiendo con Beck, una de las principales problemáticas de la sociedad contemporánea es precisamente la incertidumbre, la incapacidad de tener datos fiables para comprender y tomar decisiones ante los fenómenos de cambio medioambiental, cuyo desenvolvimiento es silencioso e imperceptible y que solo se hace sentir en eventos extremos, donde la capacidad de maniobra es reducida. Esta imperceptibilidad es la que permite la desatención de los riesgos, es decir, la relativización de su ocurrencia y la minimización de sus impactos por parte de las poblaciones y qué asuntos que son trascendentales para la supervivencia sean dejados en un segundo plano.

Las sociedades contemporáneas han aprendido a vivir con ese miedo y a restar importancia a los posibles acontecimientos, lo cual ha tenido una importante repercusión en la definición y la concreción de las soluciones que se requieren para hacer frente a los desafíos que 
supone el cambio medioambiental y sus implicaciones para la seguridad, aspectos que han sido leídos desde la perspectiva de la seguridad medioambiental.

De acuerdo con Amarilla Mena (2008), Lavaux (2007) y García (2012), en el campo de los estudios internacionales y sobre la seguridad, la temática del medio ambiente se ha configurado como un subcampo en el cual es posible identificar varias tradiciones que van desde la preocupación por los efectos del estrés ambiental (agotamiento y disputa por los recursos) hasta una comprensión holística en la que se integran aspectos de los órdenes interno y externo (Lavaux, 2007).

El que se haya planteado la seguridad medioambiental como un campo específico de reflexión y como parte de una agenda ampliada de seguridad (Amarilla, 2008) es precisamente un reflejo del posicionamiento en la sociedad de las preocupaciones por las afectaciones que pudiesen derivar del cambio medioambiental y del reconocimiento de este último como una realidad, la cual, no obstante, sigue siendo relativizada por una coalición de expertos científicos, agentes económicos y líderes políticos, quienes ponen en entredicho el carácter antropogénico y la magnitud del fenómeno.

La identificación de los problemas ambientales como riesgos ha traído consigo la búsqueda de respuestas y la identificación de campos de acción para hacerle frente, no solo a sus causas y consecuencias, siendo precisamente las apuestas por una agenda de seguridad medioambiental una expresión en ese sentido.

Atendiendo a la propuesta de Lavaux (2007), existen cuatro generaciones de estudios sobre seguridad medioambiental en el campo de los estudios internacionales. La primera, que se remonta a la década de los ochenta del siglo XX, pretendía convertir el tema medioambiental como un asunto de high politics, escudriñando las relaciones entre escasez y conflictos, así como sus efectos (migración, pobreza, tipo de sistemas económicos, entre otros), mientras que la segunda generación enfatizó en el estudio del estrés ambiental como fuente de conflictos interestatales e intraestatales en el marco de lo que se conoció como el Grupo de Totonto (Lavaux, 2007, p. 12).

Por su parte, la tercera generación se enfocó en el estudio de las dinámicas de cambio medioambiental como amenaza al bienestar 
humano. A partir de esta tendencia se estudió la relación entre medio ambiente y seguridad desde una visión optimista de las relaciones internacionales. Finalmente, la cuarta perspectiva aboga por una comprensión holística de la seguridad ambiental fundamentada en la conjunción de las tradiciones anteriores, que asume a las relaciones entre medio ambiente y seguridad como fenómenos multidimensionales que se mueven entre la cooperación y el conflicto.

Como puede observarse la trayectoria de configuración de los asuntos de la seguridad y del cambio medioambiental como problemas públicos ha estado estrechamente vinculada desde tiempos remotos, ya que la preocupación fundamental de las sociedades ha sido su sobrevivencia. No obstante, a través del tiempo se han presentado matices en su articulación, pasando de un tratamiento estrecho como asuntos indisolubles a una separación y manejo como campos diferenciados a una reintegración bajo las agendas de la seguridad medioambiental y su comprensión como componentes clave para la consolidación de un objetivo central: el bienestar humano.

Fue esencialmente con la consolidación del proyecto de la modernidad que se presentó una escisión de los temas de la seguridad y del medio ambiente, sin perderse de vista su articulación. Estos temas se compartimentalizaron, es decir, se constituyeron en campos separados de acción gubernamental, cuya gestión y agendas internas fueron delimitadas, de acuerdo con los paradigmas dominantes en cada periodo histórico, y la forma como estos determinaron la confluencia de los diversos actores sociales alrededor de ellos.

De esta manera se mantuvo como constante entre finales del siglo XIX y mediados del siglo XX la primacía de la asociación de la seguridad con la integralidad territorial del Estado nación y la subyugación de la preocupación del bienestar humano al mantenimiento de esta forma de organización social. Por lo tanto, las referencias a las condiciones de las condiciones del entorno y sus afectaciones sobre los individuos no partieron como tal desde una preocupación genuina por ellos mismos, sino por la reproducción del orden social; siendo el medio ambiente precisamente un mecanismo, un medio, para el mantenimiento de la razón del Estado. 
Pese a lo anterior, la crisis de las instituciones y del proyecto mismo de la modernidad sentó las condiciones para una reinterpretación del sentido mismo de la seguridad, del medio ambiente y de la relación hombre naturaleza, que a su vez repercutió en la rearticulación de estos temas como componentes de un mismo problema: el bienestar. Este último se ha delimitado como la conjunción de tres factores: el acceso a satisfactores de las necesidades materiales, el disfrute de un ambiente sano y la garantía de unas condiciones de confianza y estabilidad que impidan la ocurrencia de situaciones de agresión o confrontación física (la paz).

La articulación de los factores descritos se concretó en la última década como aspiración del orden mundial, a partir de la adopción de la matriz discursiva del desarrollo sostenible, la cual es, a su vez, el marco conceptual que fundamenta la agenda de los ODS. Dicho discurso es un emblema propio de la visión de la modernización ecológica, una apuesta que confía en la ciencia como eje para superar los peligros derivados de la acción humana sobre su entorno y en la capacidad de revertir las alteraciones que hemos producido como especie sobre nuestro medio.

Alrededor de este marco se han definido unas amenazas específicas, así como unos ejes de actuación y colaboración prioritarios y orientadores, que asumen como marco referencial la cooperación entre distintos actores. Dichos aspectos son caracterizados a continuación.

\section{Las manifestaciones del cambio medioambiental y su tratamiento como asuntos de seguridad}

El cambio medioambiental abarca una diversidad de fenómenos y procesos que lo hacen un tema bastante complejo, cuya interpretación ha estado mediada por la politización de la ciencia y la consecuente incapacidad de esta para reducir la incertidumbre. Por lo tanto, la movilización de distintos actores en las escalas local, nacional y global y la circulación por parte de estos de varios símbolos, imágenes y valores los que han determinado la construcción dominante sobre lo que es este proceso. 
La trayectoria que llevó a la constitución del medio ambiente en sí mismo como un campo de intervención pública puede rastrearse en los desarrollos de la ecología durante el siglo XIX, el cuestionamiento a la degradación que trajo consigo la industrialización y la consecuente urbanización en el contexto europeo, los efectos de las confrontaciones armadas sobre la disponibilidad de los recursos naturales y los estudios sobre los efectos en la salud de la calidad de aire y el uso de insumos químicos por parte de las industrias.

La percepción del agotamiento de los suelos, de la contaminación del aire y de las aguas y de los peligros que podría generar la tecnología nuclear dieron paso a que en el marco de las Naciones Unidas se planteara la atención de estos asuntos, en el marco de un interés mundial por evitar la ocurrencia de nuevas confrontaciones bélicas entre los Estados. Este impulso se vio favorecido con la identificación de la fragilidad del planeta, proporcionada por el avance de la ciencia, a raíz de las primeras fotografías satelitales y de la publicación de varios estudios que destacaban los problemas derivados del crecimiento demográfico y el avance tecnológico.

Se abrió así una etapa de la que derivaron distintos foros, acuerdos y convenciones, planteados con un mismo objetivo, garantizar la protección del planeta para permitir la permanencia de la especie humana. Mediante estos procesos se constituyó, como se mencionó en el apartado anterior, una interpretación dominante del fenómeno del cambio medioambiental, la cual se fundamentó en el clima y a la cual se subordinaron otras preocupaciones como la conservación de los ecosistemas naturales y la gestión de los construidos por la acción humana, la prevención de la degradación de los suelos, la desertización, la calidad del aire y del agua, los derechos de las otras especies entre otros aspectos.

De este modo, con la instauración del programa de las Naciones Unidas para el Medio Ambiente, la realización de la primera conferencia mundial sobre el clima en 1979, la creación del Panel Intergubernamental de Cambio Climático (IPCC, en 1989), la Declaración de Mali (1990) y la celebración de la Cumbre de la Tierra (1992), donde se sentaron las bases para la Convención Marco de las Naciones Unidas para el 
Cambio Climático, se fue estructurando el cierre discursivo en torno a este problema como el principal desafío para la humanidad.

Como tal, esta construcción discursiva no ha culminado aún y no está exenta de contradicciones. Por el contrario, su conceptualización, interpretación y reinterpretación ha continuado en el marco de las veintiuna conferencias entre las partes miembro de la CMNUCC que se han realizado desde 1995 (Mandato de Berlín) hasta 2015 con la celebración de la cumbre de Paris.

Mediante estas se definieron un conjunto sucesivo de mandatos que expresan conceptualizaciones y reinterpretaciones del fenómeno, cambiantes en el tiempo y que van de la reducción de los GEI, a partir de una participación conjunta pero diferenciada entre los Estados, de acuerdo con su nivel de desarrollo, al objetivo de evitar el incremento de la temperatura en dos grados centígrados.

Inicialmente, la apuesta adoptada se inspiraba en un modelo top down, en el cual en los acuerdos entre los participantes en las conferencias internacionales se definían las prioridades de acción internacional, para ser estas luego sometidas a la consideración de las autoridades y actores nacionales, lo cual generaba una serie de tensiones que se traducían en la tardía ratificación o no suscripción de los acuerdos, que impedía su entrada en vigor, ante el temor de los Estados de perder su soberanía. Esta es precisamente la situación que explica la entrada en vigencia en 2005 del Protocolo de Kioto creado en la COP3 en 1993.

En dicho escenario, además de crearse el Fondo Mundial para el Ambiente y de definirse como criterios orientadores la mitigación y la adaptación al cambio climático, se establecieron metas concretas de reducción de GEI, las cuales apostaron a favor de la introducción de mecanismos de mercado para estimular la participación del sector privado y no solo de los gobiernos. De esa manera surgieron los mecanismos de implementación conjunta, los mercados de carbono, los mecanismos de desarrollo limpio y los mercados voluntarios, como alternativas de conservación y reducción de gases invernadero que les permitían a los Estados que no podían cumplir las metas trazadas en su territorio nacional apoyar dichos procesos y presentarlos como resultados propios en el control del fenómeno. 
Junto a las medidas señaladas se mantuvieron los principios de cooperación entre los países en desarrollo y los países industrializados, asumiendo estos últimos la financiación y la tarea de trasferir recursos e innovaciones tecnológicas, planteándose las discusiones sobre el derecho al desarrollo y la deuda ambiental con las naciones ricas en recursos naturales sobre las cuales se ha sustentado el crecimiento de las grandes potencias, así como la trascendencia de comprometer a las naciones que más contaminan como son China y Estados Unidos (Giddens, 2011).

Por otra parte, en torno al cambio climático se ha generado una institucionalización del miedo como eje de actuación, el cual ha sido interiorizado por las poblaciones, pero, al mismo tiempo, se ha dejado en un segundo plano ante las presiones que significan las demandas de la vida cotidiana. El hecho de que no sea un asunto plenamente tangible a simple vista, junto con la dependencia ante el conocimiento científico para saber si es o no un problema conlleva a que las poblaciones asuman, interioricen e individualicen el riesgo del cambio climático y lo descarten en un segundo plano, del cual sale exclusivamente ante la ocurrencia de fenómenos climáticos extremos.

De esa manera, la construcción del cambio climático como un problema es un asunto que se le ha dejado a la ciencia y sobre el cual existen varias posturas contrarias sobre su magnitud, importancia y modo de tratamiento, en las cuales progresivamente se ha establecido el nexo con el tema de la seguridad.

Concretamente el tratamiento aislado dado a los fenómenos ambientales en el seno de la ONU a partir del programa creado para tal fin, se ha ido reestructurando por dos caminos. El primero es la adopción de disposiciones por parte de la Asamblea General y el Consejo de Seguridad que han demandado realizar informes y estudios para establecer cómo este puede afectar la seguridad. Y en segundo lugar, la integración de las agendas del desarrollo y la seguridad mediante la adopción de los discursos sobre el desarrollo sostenible y la seguridad humana.

En la construcción discursiva del medio ambiente como un problema de seguridad se ha planteado una escisión entre el cambio climático y las políticas de seguridad energética, siendo prioritario su 
tratamiento de manera articulada, como lo sugiere Giddens, si se tiene en cuenta que la base del desarrollo productivo y, por ende, de la degradación ambiental se encuentran en el uso de combustibles fósiles.

La reconvención energética y la búsqueda de fuentes alternas no se han dado con base en una discusión articulada, sino que por el contrario se han manejado como un asunto de seguridad nacional de los Estados, lo cual contrasta con los llamados a la cooperación que se plantean en la acción contra el cambio climático. A su vez, se plantea la preocupación por los suelos, el desarrollo urbano, el manejo de los residuos y la gestión de las fuentes hídricas desde una perspectiva subordinada a la reducción de emisiones, lo cual reduce las posibilidades de ver la totalidad del problema del cambio medioambiental y estructurar marcos de gobernanza para su abordaje.

Precisamente, los enfoques de la mitigación y la adaptación han conducido a que se generen una serie de iniciativas dispersas dentro de los Estados - para dar cumplimiento a los compromisos internacionales condensados en las estrategias y los programas nacionales-, en las que se descuidan asuntos prioritarios, tales como los marcos de gobernanza para la administración y el manejo de los servicios ecosistémicos, en particular, el agua.

Pese a las dificultades existentes en la construcción discursiva que se ha dado en torno al problema del cambio climático, hay varios aspectos que resaltar. En primer lugar, la identificación de que los costos de no intervención son mayores en comparación con lo que implica tomar medidas en relación con el cambio climático, lo cual quedó demostrado en el Informe Stern y fue ratificado en el informe del Secretario General "El cambio climático y sus posibles repercusiones para la seguridad" publicado el 11 se septiembre de 2009.

Otro aspecto importante es las disposiciones en materia de financiamiento resultantes de la Cumbre de París que obligan a los Estados aterrizar de las cartas de buenas intenciones a la identificar acciones concretas, con plazos y costos estimables y que se corresponde con el modelo de formulación de compromisos de abajo hacia arriba adoptado para la cumbre, en la cual cada Estado llevó plasmados los compromisos que asumirán y que fueron objeto de la negociación interna con los distintos actores nacionales. 
Finalmente, se agregan los compromisos asumidos por China y Estados Unidos, principales emisores de GEI y actores que en el pasado fueron obstáculos para la entrada de vigencia de los acuerdos o como imagen negativa que desalentaba la no acción por parte de otros Estados. Estos actores se comprometieron, con metas específicas, a reducir emisiones que generan la sensación de un nuevo marco de entendimiento y que es positivo si se tiene en cuenta el poderío de estas naciones. En estas últimas, como lo sugiere Giddens (2011), está la posibilidad de redirigir el problema del cambio climático.

\section{La seguridad medioambiental como instrumento para la concreción de la paz territorial}

Pese a los cuestionamientos sobre la viabilidad y la pertinencia de hablar de la seguridad medioambiental y las dificultades que subyacen en el régimen internacional en materia de cambio climático y protección del medio ambiente, el replanteamiento de la noción de la propia seguridad y su conexión con el medio ambiente y sus alteraciones es un marco de oportunidad para repensar la forma como hasta el momento la humanidad ha planteado la relación con la naturaleza y cómo se ha estructurado como especie.

Más allá de la identificación de las vías a través de las cuales el cambio climático puede afectar la seguridad, entendida como estabilidad territorial y del orden social, lo que debe plantease es un retorno a la comprensión de la unión indisoluble del ser humano con la naturaleza, y de qué manera este, como agente transformador y transformado por su entorno, también participa en la recreación del medio natural.

En las discusiones sobre las agendas de la seguridad medioambiental se ha planteado que el cambio climático puede representar una amenaza para la seguridad alimentaria, la salud humana y la desaceleración del desarrollo, al tiempo que puede exponer a los seres a una mayor vulnerabilidad, derivada tanto de eventos climáticos extremos como de la reducción de la capacidad de la economía para atender a sus demandas. 
A los elementos enunciados se añaden los planteamientos según los cuales el cambio climático puede estimular la migración internacional descontrolada, la desaparición de territorios y con ello de Estados nación, quedando como resultado una población apátrida y la generación de conflictos por el manejo de recursos naturales compartidos o sobre los cuales no hay una delimitación sobre su propiedad.

En conjunto, todos los temores y los riesgos detrás del cambio climático si bien no son infundados y se mantienen como amenazas, pueden ser catalogados como los propios causantes de la ineficiencia de las medidas para hacerles frente. Por lo tanto, se plantea la propuesta de cuestionar si el temor y la movilización de las imágenes negativas son instrumentos convincentes y adecuados para llamar a un cambio de conciencia y a la acción de los distintos actores sociales y de la ciudadanía en general para hacer frente a los desafíos de la humanidad.

En correspondencia se sugiere invertir la ecuación y partir de las propias ambiciones de paz que existen en lo local, junto con el reconocimiento de las potencialidades de lo local, desde una visión alternativa a los marcos extractivistas y de competitividad que promueven los enfoques de desarrollo económico local que se han promovido mundialmente en las últimas décadas y que se inspiran en las premisas del liberalismo económico.

En el mismo marco de adopción de las estrategias nacionales de mitigación y adaptación al cambio climático, así como en las experiencias de acercamiento a los mecanismos derivados del protocolo de Kioto y los proyectos que han surgido en las comunidades organizadas pueden encontrase elementos para la estructuración de apuestas de política pública alternativas, cimentadas en la construcción de lazos de confianza y corresponsabilidad.

El caso colombiano ofrece un campo analítico para observar las relaciones entre paz, seguridad y medio ambiente, al tiempo que demanda la estructuración colectiva de propuestas de ordenamiento territorial que partan de la comprensión del espacio, como totalidad, producto de la interacción entre las prácticas espaciales, las representaciones sobre su deber ser y los espacios de representación, entendidos como las formas de apropiación de los habitantes del territorio que dan lugar a una identidad y proyectos colectivos frente a su entorno. 
El prolongado conflicto armado interno y las estricciones que este ha impuesto sobre las poblaciones, que dan sentido y conforman los territorios a partir de su integración con el medio natural y social, plantea varias cuestiones para identificar las relaciones entre seguridad, medio ambiente y paz. En primera medida, se encuentra el papel que desempeñan las características del régimen político propio de los Estados nación en el procesamiento de las tensiones ante la valoración, el control, el manejo y la disposición de los recursos.

En segundo lugar, se plantea el problema de la construcción de acuerdos colectivos para gestionar los recursos disponibles y así impedir la configuración de tensiones en torno a su agotamiento o privación a ciertos sectores sociales.

Tercero, el caso colombiano, además, cuestiona los asuntos de la escasez, como la abundancia mal administrada y comprendida, sin tener en cuenta la diversidad de saberes locales lo que puede afectar los derechos de las poblaciones, las cuales, tradicionalmente, habitan los territorios donde se definen apuestas económicas trascendentales para el país.

Cuarto, esta experiencia remite a pensar los impactos sobre el medio natural derivados de las confrontaciones bélicas y la adopción de los costos de la restauración, así como la consideración de estos procesos como una vía para la reincorporación de combatientes a la vida civil. En particular, cómo pueden articularse las apuestas de mitigación y adaptación con los procesos de reintegración y de ofrecimiento de alternativas económicas viables que aseguren la satisfacción de las necesidades de las poblaciones.

\section{Conclusiones}

Atendiendo a los diferentes elementos expuestos a lo largo del documento se evidencia que el cambio medioambiental, además de ser un fenómeno físico, es el resultado de un proceso cognitivo que se mantiene en marcha. En este trasegar ha logrado reconectarse el vínculo entre ambiente y seguridad, deteriorado por las premisas del proyecto cultural, político e ideológico de la modernidad. 
En la reconexión de estas dimensiones, en particular, en la fase actual desecuritización del medio ambiente pueden encontrarse soportes, tanto para redefinir los fundamentos de las relaciones entre el hombre y la naturaleza y las diferentes comunidades humanas, desde perspectivas centradas en la equidad y el reconocimiento de la complejidad; como para generar capacidades de acuerdo con parámetros alternativos que permitan construir ágilmente acuerdos políticos incluyentes y socialmente vinculantes orientados al manejo y la protección de los ecosistemas y sus componentes en pro del bienestar humano y de los demás seres vivos.

\section{Referencias}

Amarilla Mena, M. (2008). Seguridad medioambiental ¿Es de utilidad su concepto en las Relaciones Internacionales? Anuario de la Facultad de Derecho, 26, 243-257.

Asamblea General de las Naciones Unidas (2009). El Cambio Climático y sus posibles repercusiones para la seguridad. Informe del Secretario General. Sexagésimo cuarto periodo de sesiones. Tema 114 del programa provisional. Seguimiento de los resultados de la Cumbre del Milenio.

Beck, U. (1989). La sociedad del riesgo: hacia una nueva modernidad. Barcelona: Paidós.

Convención Marco de las Naciones Unidas para el Cambio Climático CMNUCC (2008). Kyoto Protocol Reference Manual: On Accounting of Emissions and Assigned Amount.

Estenssoro Saavedra, F. (s. f.). La Geopolítica Ambiental global: el desafío del cambio climático para América Latina. Revista UNIVERSUM 2(25), pp. $57-77$

Foucault, M. (2001). Defender la sociedad. México: Fondo de Cultura Económica.

García Sánchez, I. J. (2011). El cambio climático: implicaciones para la seguridad y la defensa. Cuadernos de Estrategia, 150, 183-233 Recuperado de https://dialnet.unirioja.es/descarga/articulo/3837190.pdf.

García Rico, E. (2014). Cambio climático y seguridad en el seno de naciones unidas: ¿algo más que un debate institucional? En P. A. Fernández Sánchez, J. A. Azeredo Lopes (Dir.), M. C. Márquez Carrasco y M. I. Tavares (Comp.), Seguridad Medio Ambiental y orden internacional. IV. Encuentro Luso- Español de profesores de Derecho Internacional Público 
y Relaciones Internacionales. Barcelona: Atelier, Universidad de Sevilla y Universidad Católica Portuguesa Porto.

Giddens, A. (2009). La política del Cambio Climático. Madrid: Alianza Editorial.

Lezama, J. (2004). La construcción social y política del Medio Ambiente. México: El Colegio de México.

Giles Carnero, R. (2014). Cambio climático y derecho internacional. En P. A. Fernández Sánchez, J. A. Azeredo Lopes (Dir.), M. C. Márquez Carrasco y M. I. Tavares, Seguridad Medio Ambiental y orden internacional. IV Encuentro Luso- Español de profesores de Derecho Internacional Público y Relaciones Internacionales. Barcelona: Atelier, Universidad de Sevilla y Universidad Católica Portuguesa Porto.

Hajer, M. (1995). Politics of Environmental Discourse: Ecological Modernization and the Policy Process. United Kingdom: Oxford University Press.

Hidalgo García, M. (2015). Cambio climático y seguridad energética: un reto para la UE y EE.UU. Cuadernos de estrategia, 177, 137-180 Recuperado de https://dialnet.unirioja.es/buscar/documentos?querysDismax.DOCUMENTAL_TODO=Cambio $\% 20$ clim $\%$ C3 $\%$ A 1 tico $\% 20$ y $\% 20$ seguridad $\% 20$ energ \%C3\%A9tica \%3A \%20un \%20reto \%20para \%20la \%20UE\%20 y\%20EE.UU.\%20\&filtros.DOCUMENTAL_FACET_ENTIDAD=artrev

Lavaux, S. (2007). Degradación ambiental y conflictos armados las conexiones. Documento de Investigación, 7. Recuperado de http://www.urosario.edu.co/cpg-ri/Investigacion-CEPI/documentos/papers/Documento_7/

Moran Blanco, S. (2014). La seguridad ambiental y el cambio climático: consecuencias a nivel internacional. En P. A. Fernández Sánchez, J. A. Azeredo Lopes (Dir.), M. C. Márquez Carrasco y M. I. Tavares, Seguridad Medio Ambiental y orden internacional. IV. Encuentro Luso-Español de profesores de Derecho Internacional Público y Relaciones Internacionales. Barcelona: Atelier, Universidad de Sevilla y Universidad Católica Portuguesa Porto.

Olivier, A. G. y Domínguez Ávila, C. F. (2009). Modernización Ecológica y Políticas Ambientales: Notas para un debate. Ambiente y Desarrollo, XIII.

Oltra, C. (2005). Modernización ecológica y sociedad del riesgo Hacia un análisis de las relaciones entre ciencia, medio ambiente y sociedad. $\mathrm{Pa}$ pers, 78, 133-149. Recuperado de http://www.raco.cat/index.php/papers/ article/viewFile/40276/40564. 
Pérez, E. C. (2011). Riesgos y amenazas del cambio climático. Cuadernos de estrategia, 150, 27-65. Recuperado de https://dialnet.unirioja.es/descarga/articulo/3836663.pdf

Programa de las Naciones Unidas Para el Desarrollo. (1994). Informe sobre Desarrollo Humano. Organización de las Naciones Unidas.

Rodríguez Alcázar, J. (2012). La noción de "seguridad humana”: sus virtudes y sus peligros. Polis. Recuperado de http://polis.revues.org/5805

Roth, A. (2002). Políticas públicas, formulación, implementación y evaluación. Bogotá: Almudena Editores.

United Nations Framework Convention on Climatic Change UNFCCC. (2008) Kioto protocol reference manual on acounting of emissions and assigned amount. Recuperado de http://unfccc.int/resource/docs/publications/08_ unfccc_kp_ref_manual.pdf

Vera Esquivel, G. (2013). El Cambio Climático en el Derecho Internacional. Una visión para los ciudadanos y las empresas en el Perú y Latinoamérica. Lima: Instituto de investigaciones social cristianos. 